\title{
Die verwerwing van absolute wete as louterings- proses in Hegel se Fenomenologie van de Geest Coming to absolute knowing as a process of sublimation in Hegel's Phenomenology of Spirit
}

\author{
Hercules Boshoff \\ Fakulteit Geesteswetenskappe \\ Akademia \\ Pretoria \\ Suid-Afrika \\ E-pos: Hercules@akademia.ac.za
}

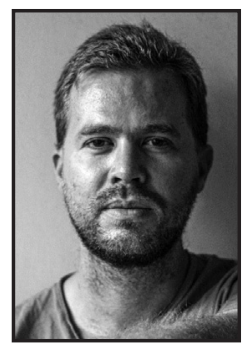

Hercules Boshoff

Hercules Boshoff is 'n dosent in filosofie en besigheidsetiek by Akademia. Hy was tot 2021 'n postdoktorale navorser in die Fakulteit Ekonomiese en Bestuurswetenskappe van die Noordwes-Universiteit (Vaaldriehoek-kampus). Hy het sy $\mathrm{PhD}$ met 'n proefskrif getiteld "Ekonomie en subjektiwiteit" (2019) aan die Universiteit van die Vrystaat verwerf, en sy MA (2015) by die Universiteit van Pretoria. Tydens beide hierdie projekte het hy onder van die mees vooraanstaande filosowe in Nederland gewerk. Sy publikasies dek Duitse idealisme, die filosofie van ekonomie, tegniek, taal, individuasie en die geskiedenis van filosofie. Hy was medestigter en voorsitter van die Chairefoon-Inisiatief, 'n vereniging wat hom beywer vir die bevordering van filosofie in Afrikaans onder nagraadse studente.
Hercules Boshoff is a lecturer of philosophy and business ethics at Akademia. Prior to his appointment at Akademia he was a postdoctoral researcher in the Faculty of Economic and Management Sciences at the University of the North West, Potchefstroom, until 2021. He obtained an MA in philosophy from the University of Pretoria in 2015 , followed by a $\mathrm{PhD}$ from the University of the Free State in 2019, the latter with a thesis entitled "Economics and Subjectivity". While studying in Holland he could engage with some of the most prestigious Dutch philosophers. His publications include German idealism, philosophy of language, philosophy of economics, individuation and the history of philosophy. $\mathrm{He}$ was co-founder and chairman of the ChairefoonInitiative, an organisation intent on promoting the study of philosophy in Afrikaans among postgraduate students. 


\section{ABSTRACT \\ Absolute knowing as a process of sublimation in Hegel's Phenomenology of Spirit}

This article examines the nature and importance of the notion of absolute knowing in Hegel's Phenomenology of Spirit. The avoidance, undervaluation and misinterpretation of absolute knowing, especially in 20th-century interpretations of Hegel's work, are challenged on the basis of Hegel's own account of absolute knowing. Three characteristics of absolute knowing stand out: first, absolute knowing is not a ready-made blueprint that can be applied blindly, but is achieved only through a laborious process that has to be completed in person and not at arms length. Second, absolute knowing can only result from the strictest possible proof in the form of complete scepticism or what Hegel termed "sich vollbringende Skeptizismus". Third, that which is criticised by the proof must be sublimated into the absolute as part of the processal nature of absolute knowing. The process reveals that self-negation, indicating shortcomings, and self-attainment, representing self-awareness of the spirit, are two sides of the same coin, namely what Hegel describes as the movement of spirit.

Hegel does not avoid the topic of truth and goes so far as to claim that those who do avoid it, in fact make a claim to truth themselves (in so far as they presuppose that the denial of truth is true) and in turn deny others. Some take Hegel's explicit reference to truth, with which his philosophy is preoccupied, to be bold and too arrogant. Consequently, the tendency recently has been to work eclectically with parts of Hegel's philosophy and dialectical approach, but largely to reject his system as a whole. Hegel was sensitive to the claims emanating from a sceptical approach to overarching truth and incorporated the critique expressed by that approach into his account of truth, along with his own critique of scepticism.

Hegel's critique of modern scepticism's denial of truth (in this case modern philosophy since Descartes) does not mean he regards it as being without merit. In fact, Hegel not only accepts, but also recommends, that any claim to truth must be subjected to scepticism in the form of science (Wissenschaft). The very essence of science (Wissenschaft) is knowing, and what else is worthy of knowing but truth? Truth, therefore, does not undermine scepticism, but rather leads scepticism to its own limits and therefore its fulfilment.

The process of leading scepticism to fulfilment is described in terms of a sublimation. Sublimation (Läuterung) is understood as an arduous process that rectifies, but does not exclude, the parts that it problematises. It is in this sense of sublimation that Hegel's famous statement that "truth is the whole" is to be understood. However, the exacting passage to truth cannot begin with the whole, as the whole has not legitimised itself, which leads Hegel to consider the way towards the whole as just as important as the destination. Natural (immediate) consciousness must therefore be allowed to present its claims to truth, after which scepticism is employed to question the claims.

This process of constantly questioning certainty corresponds with the Socratic method and, unsurprisingly, finds expression in a dialectic. The dialectic is more than a mere backand-forth exchange, but rather an unfolding of truth itself. Without such dynamism a fuller conception of truth would not take shape, and in any case would not be able to legitimise itself. To overcome the presuppositions of every stage, a certain leap over the position is required, a leap away from the position that is to be overcome, but at the same time a leap that recognises that very position. The process therefore involves active participation and expanding awareness, on the one hand, but, on the other, a measure of fate, by which Hegel means that the course of knowing is destined to lead to fulfilment (a "homecoming") in the guise of absolute knowing, a knowing that is in and for itself. 
KEYWORDS:

TREFWOORDE: absolute wete, wetenskap, waarheid, geheel, dialektiek, skeptisisme, loutering, natuurlike bewussyn, selfbewussyn, gees

\section{OPSOMMING}

Hierdie artikel ondersoek die absolute wete as sleutelbegrip in Hegel se Fenomenologie van de Geest (2013). Die vermyding, onderbeklemtoning en wanbegrip van die absolute wete in veral 20ste-eeuse interpretasies van Hegel se werk sal met behulp van sy eie uiteensetting bevraagteken word. Eerstens is die absolute wete nie 'n klaargemaakte bloudruk wat kritiekloos op die werklikheid toegepas kan word nie, maar 'n moeisame proses wat mens nie van 'n afstand kan betrag nie en waardeur ' $n$ mens self moet werk. Tweedens word aangevoer dat die absolute wete slegs die resultaat kan wees van die strengste moontlike beproewing, ${ }^{1}$ in die vorm van 'n "sich vollbringende Skeptizismus"; en derdens gaan dít wat deur die beproewing opgehef word, steeds gekoppel bly aan die absolute as deel van die prosesmatige aard daarvan. Die proses dui daarop dat selfverlies in die vorm van die uitwys van tekortkominge en selfverowering as die selfbewuswording van die gees twee kante van dieselfde muntstuk verteenwoordig, naamlik wat Hegel as die "loutering tot gees" beskryf.

\section{INLEIDING TOT DIE PROGRAM/DOELSTELLINGS VAN DIE FENOMENOLOGIE VAN DE GEEST}

Die herdenking van Hegel se 250ste geboortejaar bied die geleentheid om te besin oor sy nalatenskap sowel as die relevansie van sy denke. Ofskoon Hegel betreklik bekend is en daar selfs aandag geskenk word aan sy denke op voorgraadse vlak, is die Suid-Afrikaanse persepsie van sy denke hoofsaaklik beïnvloed deur sekondêre bronne. Om kortliks 'n paar in geen bepaalde volgorde nie, te noem: die Britse idealisme van die vroeë 20ste eeu (gevolg deur die verwerping van Hegel se denke in analitiese kringe onder die invloed van Popper se wanopvattings oor Hegel se politieke lojaliteite), ${ }^{2}$ die Marxisme soos dit in Kojeve se interpretasie van die heer-kneg-dialektiek asook die kritiese teorie gestalte kry, Franse filosofie sedert die vyftigerjare, wat deur Jean Hyppolite se lesings oor die fenomenologie van die gees beïnvloed is, die hermeneutiese filosofie sedert Gadamer, die teologie van onder andere Pannenberg en Von Rad en die sogenaamde heilsgeskiedenisvraagstuk, die swartbewussynsbeweging se bevrydingsgedrewe politieke eskatologie, meer onlangs Fukuyama se topverkoper, End of

1 Beproewing is 'n bekende Hegeliaanse begrip wat kan verwys na beide lyding en deurgronding of (herhaalde) toetsing, in die sin van "beproef alle dinge"(Paulus).

2 Houlgate (2013) som in sy inleiding tot die vertaling van die Grundlinien der Philosophie des Rechts Popper se posisie soos volg op: "In his widely read book The Open Society and its Enemies, Popper accuses Hegel of churning out 'bombastic and mystifying cant', of maintaining that 'the state is everything, and the individual nothing' and of thereby being 'the missing link' between Plato and modern totalitarianism" (Hegel 2008:vii). Kaufmann verskaf meer besonderhede: "Popper takes over such a gross mistranslation as "the State is the march of God through the world," although the original says merely that it is the way of God with the world that there should be the State, and even this sentence is lacking in the text published by Hegel and comes from one of the editor's additions to the posthumous edition of The Philosophy of Right — and the editor admitted in his Preface that, though these additions were based on lecture notes, "the choice of words" was sometimes his rather than Hegel's" (Kaufmann; toegang verkry op 08/10/2020). 
History (2006) waarin die kapitalisme se meerderwaardigheid bepleit word, en in die populêre Sloweense filosoof, Žižek, se psigoanalitiese benadering. By geen ander filosoof in die moderne filosofie (of selfs vroeër) tref mens so 'n wye verskeidenheid interpretasies aan nie. Gegewe hierdie uiteenlopendheid, kan die volgende vraag gestel word: Watter interpretasie sal ons die beste bystaan om Hegel se denke te verstaan?

Sommige van die interpretasies fokus op enkele temas in Hegel se denke, en ander op 'n formalistiese uiteensetting van konsepte, waarvan Hegel sommige nooit gebruik het nie. (Dink hier aan die bekende samevatting tese, antitese en sintese wat nog dikwels in filosofiekursusse opduik.) Mens sou egter kon betoog dat die interpretasies hul eie geldigheid het soos mens ook kan bevraagteken of 'n "korrekte" weergee van Hegel se denke hoegenaamd wenslik is, gegewe die gevaarligte wat flikker wanneer mens begrippe soos die "absolute" binne 'n 21 steeeuse konteks opper. Is dit nie maar beter om net eklekties met sommige van Hegel se konsepte te werk nie (dink hier aan begrippe soos Anerkennung of die heer-kneg-dialektiek)? Die persoon wat beswaar aanteken teen die moontlikheid van 'n "absolute waarheid", sal waarskynlik met verbasing verneem dat Hegel dié beswaar direk bespreek - reeds op die eerste bladsy van die inleiding tot die Fenomenologie van de Geest (hierna FvdG). Sy verweer is dat alle insigte aanspraak maak op waarheid (ook dié wat 'n beroep doen op die waarheid van die verklaring dat daar geen waarheid is nie). Derhalwe kan slegs die waarheid self as maatstaf vir die denke dien - hoe edel of "besorgd" die motiewe van 'n benadering wat waarheid verdag wil maak, ook mag klink: "zo verondersteld deze vrees dat dit kennen, terwijl het buiten het absolute staat, en dus ook buite de waarheid, toch waarachtig is" ( $F v d G$ W54). Volgens Cobben is Hegel se uitgangspunt "de hypotetische aanname van bewustzijn dat steeds al over de ware kennis meent te beschikken en laat zien dat deze mening gebonde is aan ongereflecteerde voorveronderstellingen" (Cobben 1996:25). Die onvermydelike aanspraak op die waarheid is dan wat $F v d G$ uit die staanspoor erken, 'n erkenning wat hom nie van die ander aansprake wegkeer nie, maar wat deur die inagneming van die aansprake op die waarheid op die spoor van die absolute wete geplaas word.

Wat sou so 'n absolute wete behels? Kan ons enigiets daaroor sê? En druis dit nie in teen die wese van die filosofie om sulke "arrogante" begrippe in te span nie? Plato het immers filosofie omskryf as 'n liefde vir wysheid (Plato 1997), ${ }^{4}$ terwyl Hegel beweer dat filosofie as 'n wetenskap (in die sin van 'n weet-skap) meer eksplisiet met waarheid self kan omgaan: “de ware gestalte waarin de waarheid existeert, kan alleen het wetenschaplijke systeem van die waarheid zijn" ( $F v d G \mathrm{~W} 11)$. Is dit egter so voor die hand liggend dat Hegel se posisie ingrypend van dié van Sokrates verskil? Wanneer Sokrates die bekende stelling maak dat hy weet dat hy nie weet nie, gee hy nie tog 'n waarheid weer, naamlik die wete dat hy nie weet nie? Ek is derhalwe van mening dat om Sokrates en Hegel se posisies as teenpole te oorweeg, oorhaastig sal wees, 'n mening wat aansluiting vind by Van Wyk Louw: "Hegel het nie vir sy eie wysbegeerte aanspraak op volledige of selfs groot oorspronklikheid gemaak nie. Wat hy beweer het, is dat sy eie wysbegeerte alle ware en waardevolle elemente van alle vroeëre denksisteme in hom opgeneem het. Byna al wat hy self bygedra het, so kon hy maklik beweer het, is om

3 Die afkorting $F v d G$ sal voortaan gebruik word vir die teks van die Fenomenologie van de Geest (2013). Die "W" verwys na die nommering van die paragraaf soos dit in die Nederlandse uitgawe voorkom (daar word benewens "W" ook "M" gebruik met ander paragraafnommers, daarom die invoeging van "W").

$4 \quad$ Hierdie bekende omskrywing van filosofie as liefde vir wysheid kom in verskeie van Plato se tekste voor, die Simposium en die Republiek die meeste (sien Plato 1997). 
die waardevolle in die vroeëre denksisteme te skei van die toevallige en persoonlike en tydgebondene, en om dit alles in een, sluitende geheel, saam te vat" (Louw 1986:327).

In ooreenstemming met Sokrates verken Hegel in die $F v d G$ verskeie kennisvelde en kom tot die slotsom dat die perke van kennis dikwels oorskry word en dat sogenaamde kenners voorgee om te weet wat hulle eintlik nie kan weet nie. Houlgate stel dit so: "Like Plato in the Republic, therefore, Hegel is interested not just in setting out his own understanding of the world, but also in educating the non-philosopher into the ways of philosophy" (Houlgate 2013:6). Die doelstelling van die Fenomenologie word voorts opgesom as Bildung, of inwyding, maar inwyding waarin? Kortom, inwyding in wat dit beteken om nie bloot te volstaan met kennis van sekere vakterme in die ambag van weet-skap nie, dit wil sê om die implikasies van kennis wyer te interpreteer. Hierdie inwyding is wat Hegel bedoel met "wetenskap". Eweseer getrou aan die nalatenskap van Sokrates, moet alle voorveronderstellings oor wat weet mag behels, volgens Hegel aan die hand van die strengste kriteria getoets word om te bepaal of dit standhoudend kan wees. Hierdie kriteria is waarheid self, en waarheid - in Hegel se vertekening - "ist das Ganze".

Daar kan afgelei word dat 'n klaargemaakte model van die geheel, waaraan daar nie 'n tekort is in die roemryke tradisie nie, ons die moeite kan bespaar om self tot die geheel deur te dring. Hegel beweer ondanks die bestaan van sulke modelle dat ons onsself eerder "de moeite kunnen besparen om überhaupt notitie te nemen van zulke voorstellingen en frasen", wat meer bepaald sal neerkom op wat Hegel "bedrog" noem ( $F v d G$ W55). Uitsprake wat slegs fokus op die kroon sonder inagneming en begrip van die grondslae, boustene, en samehang tussen die verskillende vlakke en dissiplines van die denke, dien volgens Hegel alleen die doel om wetenskap (weereens: ware weet-skap as ambag) op 'n afstand te hou. Kennis móét op 'n omvattende wyse aangebied word. Dit beteken dat ons die fyn besonderhede moet oorweeg as dit wat in dinamiese verhouding tot oorhoofse idees verkeer. Die benadering wat Hegel volg, is derhalwe een waarin die absolute benader word as "neither theory nor the impossibility of a theory, but rather a kind of method. And the examination is not directed at the thesis theories about particular objects (nature, the law, causality, etc.) but rather at epistemological and ontological theses about both what it even means to be an object, or knowledge, or reality, and consciousness, and about how these notions relate to another" (Siep 2014:65). Die absolute weet is nie 'n weg of 'n kaart wat vooraf aanwysings gee nie. Wat Hegel noem die "ry" ("Reihe"), dit wil sê die volgorde van wat betrag word, sowel as die "doel" is ewe noodsaaklik. Bygevolg sal ons hierdie weg, oftewel die metode, verder moet ondersoek alvorens opheldering kan plaasvind ten opsigte van die aard van kennis (epistemologie) en die betekenis van bestaan (ontologie).

\section{DIE WEG VAN DIE ABSOLUTE WETE}

Soos hier bo vermeld, wys Hegel daarop dat die weg tot 'n bepaalde insig so belangrik soos die insig self kan wees. Die rede hiervoor is dat kennis nie bloot as sodanig aanvaar kan word nie; die toetsing en die konkretisering daarvan is eweneens belangrik. Met ander woorde: die werklikheid staan nie los van die idees nie. Desnieteenstaande beteken dit dat ons onmiddellike kennis nie as gesaghebbend kan ag alvorens die implikasies daarvan deurdink word nie. Die bemiddeling tussen die abstrakte en die konkrete is dan die weg wat die $F v d G$ inslaan.

Wat sal egter as maatstaf vir die beproewing gebruik kan word indien die ware, die geheel, nie voorhande is nie? En verder: hoe sou selfs die ware as geheel sigself kan regverdig? Dit wil voorkom of die absolute wete nie van meet af as gesaghebbend voorgehou kan word nie, 
want daar sal altyd vrae ontstaan oor die maatstaf waaraan dit gemeet kan word. Hierdie bedenking, wat in Descartes se denke reeds die gestalte van radikale twyfel inneem, word volgens Cobben deur Hegel as 'n keerpunt in die geskiedenis van filosofie beskou. Dit mag so wees dat Hegel dit as 'n belangrike moment beskou, maar dit beteken nie dat hy Descartes se begrip van twyfel kritiekloos aanvaar nie - in 'n teks oor die verhouding van die skeptisisme tot filosofie wat uit 1801 dateer, wys Hegel daarop dat "the ideas about skepticism in common circulation are extremely formal and the noble nature which skepticism possesses in its true form is habitually perverted into a common hidingplace and excuse for nonphilosophy in the most recent times" (aangehaal in Forster 1989:9). Hegel vind dus konseptueel sterker aansluiting by die antieke skeptisisme soos vervat in die geskrifte van Sextus Empiricus. Skepsis word in verband gebring met isosthenia, wat beteken om gewig te gee aan beide kante.

Ons kan ons nie beroep op kennis wat vooraf gegee word nie, maar ook nie op iets wat slegs apodikties sin maak nie. Die enigste moontlikheid wat vir die moderne individu oorbly, is klaarblyklik volharding in die skepsis, wat Hegel beskryf as die "weg des Zweifels" (wat mens laat dink aan Van Wyk Louw se waarneming dat die filosofie tuis is in onsekerheid). Daar is ander moderne denkers wat twyfel as middel tot 'n doel inspan. Prominent onder hulle is Descartes, wat vanuit Hegel se perspektief die skepsis slegs op sekere kwessies toepas, naamlik die aard van empiriese ervaring. Hy laat egter na om byvoorbeeld sy aanvaarding en redevoering vir die bestaan van God te betrag (wat derhalwe by hom bloot plaasvervangers vir die gebrek van begronding vanuit die ervaring is). Daarenteen is dit vir Hegel belangrik om konsekwent te wees in die toepassing van die skepsis. Dit beteken dat alle insig aan die strengste skeptiese oorweging onderwerp moet word. Sodanige onderdompeling in die skepsis lei tot wat Hegel tipeer as 'n "sich vollbringende Skeptizismus". Die voltrekking van die skeptisisme vind dan weer aansluiting by Hegel se lees van die antieke skeptisisme in drie opsigte: eerstens dat verskillende perspektiewe teen mekaar opgeweeg moet word in die sin van isosthenia; tweedens dat dit 'n doel dien, soos saamgevat word deur Forster as "the ancient skeptics valued suspension of belief (epoche) as the key to mental quietude (ataraxia) and hence happiness (eudamonia)" (Forster 1989:10); en derdens dat dit mens nie by een bepaalde insig wat oor ander triomfeer, hoef uit te bring nie, maar eerder by 'n bewustheid van die geheel. ${ }^{5}$

Een van die verrassende aspekte van die ontplooiing van die skepsis in Hegel se denke is dat dit hom nóg by 'n apatiese sinisme, nóg by 'n solipsisme uitbring; dit verteenwoordig 'n proses wat uitloop op absolute weet deur die bewussyn, selfbewussyn, rede, gees en religie. Die gewaarwordingsgebeurtenis of -moment konstateer dus subjektiwiteit anders as by Descartes, en volgens sommige interpretasies ook Kant, by wie ervaring hoogstens 'n bevestigende rol kan vervul. Alleen deur skeptiese vraagstelling ontdek ons die komplekse aard van die sosiale werklikheid en die samehang tussen verskynsels. Skepsis is vir Hegel die begin van absolute weet of ken in wetenskapsbeoefening.

Die skepsis kan voltrek word volgens die weg van die wetenskap, wat nie sonder meer kan aanspraak maak op kennis nie, maar langs ander gestaltes van die denke as 'n "verskyningsvorm van het weten" sy plek moet inneem. Filosofie, wat "die Wissenschaft der Wissenschaften sein will, ist zuerst ein erscheinendes Wissen unter anderem” (Pöggeler

\footnotetext{
Hegel lewer egter in die $F v d G$ ook 'n fel kritiek op die antieke skeptisisme, die "absolute dialektiese onrustigheid" wat "ronddool" in die niet-wezenlijkheid, as dit waarin, tesame met die stoïsynse benadering, die individu sigself van die werklikheid afsonder, 'n afsondering wat aanleiding gee tot wat hy noem die "ongelukkige bewussyn" ( $F v d G$ W121). Nogtans hou Hegel hom by sy voorneme om die absolute deur die skepsis te benader, maar dit bring hom by ander gevolgtrekkings, omdat hy die skepsis tot logiese voltrekking wil bring, soos wat verduidelik sal word.
} 
1973:237). Wetenskap kan daarom nie die blote feit van sy bestaan of voornemens om te ken as legitimering van sy uitsprake aanbied nie, en moet hom verlaag tot die vlak van die skyn, en hierdie skyn 'n gang laat gaan - dit moet die skyn self “onderneem”. Hierdie onderneming kom terugskouend neer op "a journey from immediate spirit or sensible, common-sense consciousness to authentic knowledge or philosophical science" (Flay; toegang verkry op 2020/11/05).

Die wetenskap is daarom in die eerste instansie geen verhewe noëtiese dissipline wat in afsondering beoefen word nie, en kan hom slegs regverdig deur stapsgewys die skyn - dit wat onmiddellik in die bewussyn opkom - te betrag. Hegel voer aan dat die wetenskap begin by wat hy die natuurlike bewussyn noem. Die natuurlike bewussyn kan eenvoudig beskryf word as ' $n$ "standpoint of consciousness which knows objects in their opposition to itself and knows itself in opposition to them" (Siep 2014:55). Die aanspraak wat die natuurlike bewussyn vanuit die onmiddellike ervaring op waarheid maak, word egter nie "bevredig" nie, en gee aanleiding tot wat Hegel beskryf as 'n "verlies aan sigself", wat verstaan word as deel van die weg of ontwikkelingsgang van die natuurlike bewussyn. Die weg van selfverlies beweeg dan deur 'n reeks "door haar aard voorbestemde staties" en kan slegs "door de volledige ervaring van zichzelf tot de kennis komt van wat ze op zichzelf is" ( $F v d G$ W55). Die natuurlike bewussyn loop dus volgens Taylor uit op 'n "contradiction and itself points beyond itself to a more adequate form" (Taylor 1975:128). Hierin sien ons dus weer 'n soort Sokratiese inslag, 'n gelate geduld wat insigte aandagtig toelaat om self te ontplooi en in hierdie ontplooiing besef wat sy eie beperking is, wat 'n oorgang noodsaak.

Selfverlies is gevolglik die eerste "unvollendeten" stap tot ware kennis van sigself. Ofskoon Hegel die woord "voorbestem" ("vorgesteckter") aanwend om die uiteinde van die proses te beskryf, is die weg van die bewussyn allermins vanselfsprekend of voorspelbaar; dit kom neer op wat Hegel beskryf as 'n loutering tot gees, waartydens gegewe opvattings deurtastend oorweeg, geëvalueer en verwerk word tot nuwe insigte. Die aspek van betrokkenheid van die bewussyn in die verwerwing van kennis is wat Hegel se weergawe van skepsis van ander vorme daarvan onderskei. Die "negatiwiteit van alle enkelheid en van alle onderskeid" word dus nie à la Nietzsche deur 'n Dionisiese Ur-eine ${ }^{6}$ vervang nie, maar wel deur dit waarin onderskeid toegeëien word as deel van sigself. Die samehang tussen eenheid en onderskeid, oftewel die wordingsproses van die absolute, is loutering.

Die komponent van loutering is waarskynlik onderskat in die formalistiese handboekweergawes van Hegel se denke: loutering verwys na die manifestering en onderweg-wees van die absolute weet as selfbewuswordingsproses. Loutering is 'n nieweglaatbare bestanddeel van Hegel se denke. Dit beteken dat die persoon wat hom in Hegel se denke wil verdiep, nie die stappe van 'n afstand, reeds geskool in die een of ander insig, kan oorskou nie, maar die gang van die gees self moet deurloop. Deur skepsis, wat normaalweg as die teenhanger van waarheid beskou word, as weg tot waarheid te identifiseer, wys alreeds daarop dat die leser hom moet voorberei op 'n stamperige pad. Vanuit die perspektief van die gees kan die gang egter beskryf word as 'n tuiskoms.

Loutering, die begrip waarmee die tuiskomsproses van die gees beskryf word, geskied eerstens as eliminering van selfvoldane kennisvorme - kennisvorme wat aanspraak maak daarop dat die geheel daarin opgeneem is, terwyl die teenoorgestelde met hierdie kennisvorme se aansprake die geval is, naamlik dat dit die geheel tot 'n deel verskraal. Eliminering in die

Vergelyk hier Nietzsche se gedagtes oor tragedie in sy The Birth of Tragedy and other Writings (1999). 
vorm van 'n volbringende skeptisisme is volledig, omdat dit nie die gegewe van dink in die gewaad van Descartes se ego vooropstel as voorwaarde vir elke ander insig nie, maar die denke ook as oomblik en deel van 'n ontvouende proses begryp - 'n proses wat sig stelselmatig voordoen as die geheel, in die sin van opheffing ("Aufhebung"). Dit beteken dat die geheel die eliminering van kennis moontlik maak, omdat die vraag na waarheid, na die geheel, implisiet in die behoefte tot eliminering van valse uitgangspunte opgesluit is. 'n Mens kom dus tot die gevolgtrekking dat die geheel die resultaat en skepping van denke is, maar dis 'n insig wat nie uit die denkarbeid kom nie; jy is reeds deel van die geheel waaruit die vraag na die geheel as die vraagstuk van die individu na vore tree; daarom kan die denke tweedens die vraag na die geheel nou eksplisiet stel ('n vraagstelling wat by die eerste oogopslag hubristies mag voorkom, maar wat in die ontplooiing daarvan juis vereis dat vooropgestelde idees bevraagteken word omdat die vraag na die geheel by uitstek eliminering van valse insigte vereis). Daarvoor is daar nie 'n pasklaar metode wat mens kan toepas nie: die hede kan byvoorbeeld deur lesse uit die verlede uitgedaag word, terwyl uitgediende begrippe insgelyks deur huidige verwikkelinge irrelevant gemaak kan word. Die gang van die gees is nie een waarvan ons bloot toeskouers is nie, ons is betrokke daarby, ons word daardeur gelouter, dit wil sê verontwaardig, en tot die betragting van die ware as geheel opgeroep.

Die dialektiek speel ' $n$ onontbeerlike rol in die ontvouing van die proses waartydens "apparently stable thoughts reveal their inherent instability by turning into their opposites and then into new, more complex thoughts" (Houlgate 2005:38). 'n Belangrike sin uit die inleiding lui soos volg: "Das Bewußtsein aber ist für sich selbst sein Begriff, dadurch unmittelbar das Hinausgehen über das Beschränkte und, da ihm dies Beschränkte angehört, über sich selbst; mit dem Einzelnen ist ihm zugleich das Jenseits gesetzt, wäre es auch nur, wie im räumlichen Anschauen, neben dem Beschränkten” (Hegel 1988:63). Vry vertaal: Die bewussyn is op sigself begrip, en deur die begrip oorgang oor sy aanvanklike beperking. Omdat die beperking aan hom (die bewussyn) behoort, is begrip 'n sprong oor sigself; en met die enkelheid (wat met die begripsvorming gestalte kry) is vir hom tegelyk die oorgang in die hand gewerk, en word dit (die oorgang) langs sy beperking of eindigheid geplaas $(F v d G)$. Die enkelheid verwys na die begrip wat ontstaan uit die sprong oor die beperking, 'n sprong wat die bewussyn 'n posisie van refleksie ten opsigte van sigself bied. Pöggeler (1973:240) wys daarop dat hierdie tipe bewoording van Hegel dikwels dui op 'n "Umkehrung des Bewusstseins". Die gewaarwordinge bewys nie die geldigheid van hul waarnemings nie; die teendeel vind eerder plaas, naamlik dat 'n verontwaardiging ten opsigte van die aanvanklike standpunt plaasvind. Die verontwaardiging behoort nie binne die konteks van die geheel as belemmerings verstaan te word nie, maar moet beskou word as aktiveerders wat tot nuwe insigte kan aanleiding gee. Soveel as wat verontwaardiging die leuen blootstel, kan dit ook die weg baan vir 'n dieper ondersoek in die waarheid. Selde word waarheid sonder verontwaardiging bereik. Dit sou daarom op 'n oorvereenvoudiging neerkom om die Fenomenologie in terme van 'n induktiewe of deduktiewe benadering te probeer beskryf. Die regte beskrywing van die aanslag is dialekties. Wat hiermee bedoel word, is dat die absolute wete nie 'n abstraksie is wat afgesonderd van die werklikheid bestaan nie, maar gestalte gee en gestalte kry in die werklikheid.

Wat die gestaltevorming van die proses betref, word dikwels op die historiese verloop van die bewussyn in Hegel se werk gewys. Dat historiese momente 'n sterk rol speel in die ontplooiing van die bewussyn is gewis, maar oor 'n soort chronologies-logiese verloop van die genoemde proses in Hegel se denke is daar onder kenners nie samehorigheid nie. Wat die $F v d G$ betref, spring Hegel dikwels rond tussen die moderne, antieke en Middeleeuse en selfs argaïese tydsgewrigte om gestalte aan die vloei van 'n argument te gee. Die voorlaaste hoofstuk 
verwys byvoorbeeld terug na die argaïese godsdienste as die denksfeer waarin die begrip van die absolute as omvattende bewussyn ter sprake kom. 'n Logiese ontplooiing van argumente wat bepaalde konkrete gestaltes aanneem, is dus waarskynlik die oogmerk van die werk eerder as 'n suiwer liniêr-historiese ontplooiing. Wat die kartering van Hegel se eie denke in die geskiedenis van filosofie betref, moet ' $n$ bewustelike modernistiese aanslag in sy denke in ag geneem word (hy wys in die voorwoord op 'n "nuwe" tyd wat vir die denke aangebreek het), wat volgens Houlgate die stempel dra van "the claim to freedom that finds expression in Kant's moral philosophy, the French Revolution and the modern constitutional state" (Houlgate 2005:115). Hierby voeg Houlgate ook die moderne wetenskap. Dus sou mens kon sê dat Hegel se werk gekwalifiseerd modern is, nie modern in terme van 'n onbewuste meesleuring deur die geskiedenis nie, maar een wat bewus word van die proses waaruit dit tot stand kom, as iets waaraan die bewussyn wesenlik deelagtig is.

Afgesien van die uiteensetting van die verloop van die natuurlike bewussyn in die absolute wete, is daar twee ander perspektiewe op gebeure wat ter sprake kom in die teks. Dit is die oorsigtelike perspektief van die filosoof-outeur en die fenomenologiese perspektief van die leser, die een wat toekyk. Sonder die perspektief van die outeur, sou die absolute byvoorbeeld nie in die inleiding geopper kon word nie. Die drie posisies word egter slegs in die laaste instansie tot ooreenstemming gelei (Cobben 1996:25). Die fenomenoloog (leser) neem alleen waar wat in die teks afspeel ("das reine Zusehen"), terwyl die natuurlike bewussyn self die beproewings ter sprake in die teks deurmaak (Houlgate 2013:17). Die outeur, of filosoof, wag as't ware die natuurlike bewussyn in sonder om daaraan voor te skryf wat die oplossing van elke benadering is, bewapen slegs met die skeptisisme wat op Sokratiese wyse aan die bewussyn voorgehou word. Hierdie inwag word genoodsaak omdat Hegel die wetenskap sonder voorveronderstellings wil toelaat om die natuurlike bewussyn sy gang te laat gaan. Die weg, soos Houlgate uitwys, het "very little to do with the method of "thesis - antithesis - synthesis", en kan beter beskryf word as "organic method whereby presuppositionlessness thought freely and necessarily determines itself"” (Houlgate 2013:38). Wat word egter bedoel met denke sonder voorveronderstellings, gegewe die feit dat Hegel deurlopend ruimte skep vir die onmiddellike ervaring om aanspraak op waarheid te maak? Dit is nie 'n eenvoudige vraag om te beantwoord nie. Waaroor dit hier handel, om Cobben se aanhaling weer te opper, is om "ongereflekteerde voorveronderstellinge" die hoof te bied. 'n Standpunt kan nie sonder meer aanvaar word sonder regverdiging of refleksie nie. By Hegel is die selfbewussyn bewussyn wat oor sigself reflekteer. Wat stel mens in staat om te reflekteer? Die begrip van selfverlies kom ook hier ter sprake. Om 'n werklike perspektief of "begrip vir sigself" te kry, vereis 'n oorsig wat op meer berus as die weergee van die aanvanklike posisie. Ek sal dit nie so sterk soos Houlgate stel dat Hegel geheel en al denke sonder voorveronderstellings voorstaan nie (mens moet in gedagte hou dat Houlgate se beskrywing op die Wissenschaft der Logik afgestem is, maar dat sy beskrywing terselfdertyd in 'n boek staan wat 'n oorkoepelende oorsig oor Hegel se idees wil aanbied); dit wil voorkom of Hegel hier die onmiddellike ervaring as 'n meewerkende maar onvoldoende oorsaak beskou. Dit wil sê die absolute word nie bepaal deur enigiets buite sigself nie, anders sal dit per definisie nie absoluut wees nie.

Die "voorbestemde" aard van die absolute wys noodwendig op die koppeling tussen weg en doel, maar 'n koppeling wat wedersyds bepalend is. In hierdie sin word die absolute aan die Christelike begrip van absolusie of kwytskelding en vergiffenis gekoppel, nie as 'n tipe voorbestemming waartoe mens passief aangedryf word nie, maar as vrywordingsmoontlikheid in die sin van 'n refleksiewe selfbewustheid wat met ' $n$ immanente louteringsproses te make het. Die absolute, wat die natuurlike bewussyn deurskemer, bewys sigself voortdurend as 
onbepaald, en daarom vry. Hierdie vryheid is 'n verwerwing wat nie sonder loutering bereik kan word nie. In die inleiding tree daar dan 'n paar temas na vore: bevestiging dat die implisering van waarheid onvermydelik is en daarom geprioritiseer moet word; dat skeptisisme die enigste weg bied wat bo verdenking ingeslaan kan word om die waarheid te verken, maar dat hierdie proses voltrekking moet bereik in 'n beeld van die geheel, en dat hierdie beeld hom moet kan verantwoord ten opsigte van die verskillende dele en die verhouding waarin hulle tot mekaar en die geheel staan.

\section{BIBLIOGRAFIE}

Boshoff, HJ. 2019, Ekonomie en subjektiwiteit. Ongepubliseerde proefskrif. Bloemfontein: Universiteit van die Vrystaat.

Cobben, P. 1996. Postdialektische Zedelijkheid: Ontwerp voor een Hegeliaans antwoord op Heidegger, Habermas, Derrida en Levinas. Kampen: Kok Agora.

Flay, JC. https://www.jstor.org/stable/20125668 . Toegang verkry op 11/05/2020.

Forster, M. 1989. Hegel and Skepticism. Cambridge: Harvard University Press.

Fukuyama, F. 2006. The End of History and the Last Man. Washington: Free Press.

Hegel, GWF. 1988. Phänomenologie des Geistes. Hamburg: Felix Meiner Verlag.

Hegel, GWF. 2005. De filosofie van de objectieve geest: over recht, moraal en politiek. Amsterdam: Boom uitgevers.

Hegel, GWF. 2008. Outlines of the Philosophy of Right. Oxford: Oxford University Press.

Hegel, GWF. 2013. Fenomenologie van de Geest. Vertaal deur Willem Visser. Amsterdam: Boom Uitgevers.

Houlgate, S. 2005. An Introduction to Hegel: Freedom, Truth and History. Cornwall: Blackwell Publishing.

Houlgate, S. 2013. Hegel's Phenomenology of Spirit. London: Bloomsbury.

Inwood, M. 1992. A Hegel Dictionary. Oxford: Blackwell Publishers.

Kaufmann, W. https://www.marxists.org/reference/subject/philosophy/works/us/kaufmann.htm Toegang verkry op 08/10/2020.

Louw, NP van Wyk. 1986. Versamelde Prosa: 2. Kaapstad: Human \& Rousseau.

Nietzsche, FW. 1999. The Birth of Tragedy and Other Writings. Cambridge: Cambridge University Press.

Nietzsche, FW. 2000. Die Geburt der Tragödie aus dem Geiste der Musik. Frankfurt: Insel.

Plato, 1997. Complete Works. Indianapolis: Hackett Publishing Company Inc.

Pöggeler, O. 1973. Hegels Idee einer Philosophie des Geistes. Freiburg: Verlag Karl Alber.

Siep, L. 2014. Hegel's Phenomenology of Spirit. Cambridge: Cambridge University Press.

Taylor, C. 1975. Hegel. Cambridge: Cambridge University Press. 